\title{
ANALISIS PENGARUH PENDAFTARAN TANAH SISTEMATIS LENGKAP (PTSL) TERHADAP KEPUASAN MASYARAKAT PADA KANTOR PERTANAHAN KABUPATEN ACEH TAMIANG
}

\author{
Rini Andriani ${ }^{1}$, Fairus ${ }^{2}$ \\ Jl. Prof. Dr. Syarief Thayeb, Meurandeh, Langsa Lama \\ Program Studi Matematika, Fakultas Teknik, Universitas Samudra, Langsa, Aceh \\ Email: ${ }^{1}$ rini.scione@gmail.com, ${ }^{2}$ fairuz@unsam.ac.id
}

\begin{abstract}
ABSTRAK
Pendaftaran Tanah Sistematis Lengkap (PTSL) merupakan proses pendaftaran tanah untuk pertama kali yang dilakukan secara serentak dan meliputi semua objek pendaftaran tanah yang belum didaftarkan didalam suatu wilayah desa. Pentingnya PTSL dalam kehidupan masyarakat adalah agar tidak terjadi sengketa atau saling klaim atas lahan yang terdaftar. PTSL ini bertujuan untuk menjamin kepastian dan perlindungan hukum atas kepemilikan tanah. Tujuan penelitian ini adalah untuk mengetahui kepuasan masyarakat terhadap pelayanan Kantor Pertanahan Kabupaten Aceh Tamiang dan pengaruh kepuasan masyarakat terhadap Informasi Pendaftaran Tanah Sistematis Lengkap (PTSL) di Desa Seuneubok Punti Kabupaten Aceh Tamiang. Data yang digunakan adalah data primer yaitu data yang diperoleh secara langsung dari masyarakat desa melalui penyebaran kuesioner di Desa Seuneubok Punti Kabupaten Aceh Tamiang. Kuesioner berisikan 14 pertanyaan mengenai kepuasan masyarakat, 15 pertanyaan mengenai informasi Pendaftaran Tanah Sistematis Lengkap (PTSL). Data yang didapat dari hasil kuesioner di analisis menggunakan metode statistik deskriptif dan metode regresi linier sederhana pada aplikasi SPSS 20,0. Berdasarkan analisis yang dihasilkan, didapatkan nilai signifikan lebih kecil dari $0.05(0,00<0.05)$, sehingga dapat di simpulkan bahwa variabel Independen dapat berpengaruh terhadap Variabel Dependen selain itu didapat koefisien determinasi RSquare sebesar 0.193 atau sebesar $19 \%$ dan dapat disimpulkan bahwa pengaruh kepuasan masyarakat terhadap Informasi Pendaftaran Tanah Sistematis Lengkap (PTSL) di Desa Seuneubok Punti adalah 19,3\% sedangkan 80,7\% dipengaruhi oleh faktor lain selain Informasi Pendaftaran Tanah Sistematis Lengkap (PTSL).
\end{abstract}

Kata kunci: Pendaftaran Tanah Sistematis Lengkap, Kepuasan Masyarakat, Kabupaten Aceh Tamiang, Regresi Sederhana, SPSS.

\begin{abstract}
Complete Systematic Land Registration (PTSL) is a land registration process for the first time that is carried out simultaneously and includes all land registration objects that have not been registered in a village area. The importance of PTSL in people's lives is that there are no disputes or mutual claims over the registered land. This PTSL aims to ensure legal certainty and protection of land ownership. The purpose of this study was to determine how much community satisfaction with the Aceh Tamiang. District Land Office services and how much influence community satisfaction has on Complete Systematic Land Registration Information (PTSL) in Seunebok Punti Village, Aceh Tamiang Regency. The data used are primary data, namely data obtained directly from the village community through distributing questionnaires in Seuneubok Punti Village, Aceh Tamiang Regency. The questionnaire contains 14 questions regarding community satisfaction, 15 questions regarding complete systematic land registration information. The data obtained from the results of the questionnaire were analyzed using descriptive statistical methods and simple liniear regression methods in the SPSS 20.0 application. Based on the resulting analysis, a significant value was obtained that is smaller than $0.05(0.00<0,05)$, so it can be concluded that the independent variable has an effect on the dependent variable besides that the coefficient of determination $R$-Square is 0,193 or 19,3\% and it can be concluded that the effect of community satisfaction on Complete Systematic Land Registration (PTSL) information in Seuneubok Punti Village is 19,3\% while the remaining 80,7\% is influenced by other factors, while Information on Complete Systematic Land Registration (PTSL).

Keywords: Complete Systematic Land Registration (PTSL), Community Satisfaction, Aceh Tamiang District, 1. PENDAHULUAN$$
\text { Regression, SPSS. }
$$

Jurnal Gamma-Pi, Volume 3 Nomor 2 Desember 2021 
Tanah merupakan peranan yang sangat penting dalam masyarakat. Negara berhak untuk mengatur, menyelenggarakan, menggunakan dan menentukan hubungan hukum antara orang perorang dengan bumi, air dan ruang angkasa. Dalam pelaksanaannya hak menguasai oleh Negara akan diberikan kepada daerah atau masyarakat adat sepanjang tidak bertentangan dengan kepentingan nasional. Pengaturan masalah pertanahan diatur dalam Undang-Undang No.5 Tahun 1960 tentang Peraturan Dasar Pokok-pokok Agraria atau dikenal Undang-Undang Pokok agrarian (UUPA). Dalam undang-undang ini memuat tentang kebijakan pertanahan Nasional yang menjadi dasar pengelolaan tanah di Indonesia.Kewenangan urusan Pertanahan tetap menjadi urusan pemerintah pusat dalam pengelolaannya.Untuk itu pemerintah membentuk Badan Pertanahan Nasional (BPN), yang bertugas merumuskan dan melakukan kebijakan penetapan hak atas tanah, pendaftaran tanah, dan pemberdayaan masyarakat.

PTSL merupakan proses pendaftaran tanah untuk pertama kali, yang dilakukan secara serentak dan meliputi semua objek pendaftaran tanah yang belum didaftarkan didalam suatu wilayah desa atau kelurahan atau nama lainnya yang setingkat dengan itu. Metode PTSL ini merupakan inovasi pemerintah melalui kementrian ATR/BPN untuk memenuhi kebutuhan masyarakat.

\section{METODE PENELITIAN}

Penelitian ini merupakan penelitian kuantitatif yang menggunakan data primer, dilaksanakan di Desa Seunebok Punti pada bulan Februari 2021. Metode pengumpulan data yang digunakan antara lain dengan melakukan penyebaran daftar pertanyaan (Kuesioner) kepada responden, yaitu masyarakat yang memiliki tanah di Desa Seunebok Punti, dan masyarakat pertama kali mengajukan permohonan pembuatan sertifikat tanah dengan alas hak (Akta Jual Beli, Segel Hibah, Segel Jual Beli, PBB, Kwitansi dan lainlain).pemberian Kuesioner deberikan kepada masyarakat Desa Seunebok Punti Secara Langsung. Responden dalam penelitian ini berjumlah 47 Responden. Data dianalisis dengan menggunakan SPSS 20.0 berikut :

Adapun hipotesis yang akan diuji sebagai

$H_{0}$ : Tidak adanya pengaruh pendaftaran Tanah Sistematis Lengkap (PTSL) Terhadap Kepuasan Masyarakat.
$H_{1}$ : Terdapat adanya Pengaruh Pendaftaran Tanah Sistematis Lengkap (PTSL) Terhadap Kepuasan Masyarakat.

\section{HASIL DAN PEMBAHASAN}

Adapun terdapat beberapa Kisi - Kisi

Operasional Variabel

\section{Kepuasan Masyarakat}

Menurut Lukman dalam (Semil, 2018) Kepuasan dapat didefenisikan sebagai "tingkat persaan seseorang atau kesenjangan antara harapanharapan atau keinginan-keinginan konsumen dengan kenyataan yang mereka alami.Indikator kepuasan masyarakat dapat dilihat di tabel 1 .

Tabel 1. Operasional Variabel Kepuasan Masyarakat

\begin{tabular}{|c|c|c|}
\hline Variabel & Dimensi & Indikator \\
\hline \multirow[t]{5}{*}{$\begin{array}{l}\text { Kepuasan } \\
\text { Masyarakat }\end{array}$} & pelayanan & $\begin{array}{l}\text { 1. Pelayanan yang sigap, } \\
\text { cepat dan jelas. }\end{array}$ \\
\hline & & $\begin{array}{l}\text { 2. Mamp memberikan } \\
\text { Informasi yang baik } \\
\text { serta jelas dan Pasti. } \\
\text { 3. Kepastian biaya dan } \\
\text { jadwal pelayanan }\end{array}$ \\
\hline & $\begin{array}{c}\text { Sarana dan } \\
\text { Prasarana }\end{array}$ & $\begin{array}{l}\text { 1. Ruang tunggu yang } \\
\text { nyaman san bersih. }\end{array}$ \\
\hline & & $\begin{array}{l}\text { 2. Amannya Prasarana } \\
\text { yang telah di sediakan. } \\
\text { 3. Fasilitas yanag lengkap }\end{array}$ \\
\hline & $\begin{array}{c}\text { Kemudahan } \\
\text { Lainnya }\end{array}$ & $\begin{array}{l}\text { 1. Lokasi dengan mudah } \\
\text { di jangkau. }\end{array}$ \\
\hline
\end{tabular}

Sumber: (Semil,2018)

\section{Informasi Pelayanan Pendaftaran Tanah Sistematis Lengkap (PTSL) \\ Menurut (Riyanto, 2018) Pelayanan}

Merupakan salah satu bentuk kegiatan/aktifitas yang diberikan oleh satu Pihak lain yang memiliki hubungan dengan tujuan untuk dapat memberikan kepuasan kepada pihak kedua yang bersangkutan atas barang dan jasa yang diberikan. Sedangkan menurut (Semil, 2018) hakikat pelayanan publik adalah pemberian pelayanan yang memuaskan kepada khalayak umum (masyarakat) sebagai perwujudan dari kewajiban aparatur pemerintah sebagai abdi negara dan abdi masyarakat. Pelayanan yang dilakukan Kantor Pertanahan Kabupaten Aceh Tamiang merupakan Pelayanan Publik, karena dilakukan aparatur pemerintah terhadap masyarakat. Indikator Informasi Pelayanan PTSL dapat dilihat ditabel 2. 
Tabel 2. Operasional Variabel Informasi Pelayanan PTSL

\begin{tabular}{lcc}
\hline Variabel & Dimensi & \multicolumn{1}{c}{ Indikator } \\
\hline Pelayanan & Atitude & 1. Pelayanan dengan ramah \\
Publik & (Sikap) & $\begin{array}{l}\text { dan sopan } \\
\text { 2. Pelayanan memberikan } \\
\end{array}$ \\
& & $\begin{array}{l}\text { Informasi yang jelas } \\
\text { 3. Pelayanan dengan } \\
\text { penampilan serasi. }\end{array}$
\end{tabular}

Attention 1. Mampu Mendengarkan (perhatian) dan memahami kebutuhan masyarakat.

2. Mampu Menghargai Keluhan yang terjadi Kepada Masyarakat.

Action 1. Mencatat dan (Tindaka menegaskan kebutuhan n) masyarakat.

2. Keadilan dalam memberikan pelayanan dan mengucapkan terimakasih pada akhir pelayanan.

Sumber: (Rangkuti,2017)

\section{Uji Instrumen Penelitian}

\section{A. Uji Normalitas}

Uji Normalitas adalah pengujian data untuk melihat apakah nilai residual terdistribusi normal atau tidak (Imam Al-Ghazali, 2011:29). Uji normalitias ini menggunakan metode uji analisis Metode Kolmogrov-Smirnov.

Dasar Pengambilan Keputusan dalam Uji Kolmogorov-Smirnovadalah :

1. Jika Nilai Signifikansi $>0.05$, maka nilai Residual berdistribusi Normal.

2. Jika nilai Signifikansi $<0.05$, maka nilai Residual tidak berdistribusi Normal.

Tabel 3. Uji Normalitas

\begin{tabular}{cccc}
$\begin{array}{c}\text { Niai } \\
\text { Kolmogo } \\
\text { rov- } \\
\text { Smirnov }\end{array}$ & $\begin{array}{c}\text { Asym } \\
\text { p.Sig }\end{array}$ & Kriteria & Ket. \\
\hline 0,518 & 0.951 & $>0.05$ & $\begin{array}{c}\text { Data Berdistribusi } \\
\text { Normal }\end{array}$ \\
\hline $\begin{array}{l}\text { Sumber : Hasil Uji } \\
\text { Normalitas Tahun 2021 }\end{array}$ & SPSS $20.0 \quad$ terhadap Uji \\
$\begin{array}{l}\text { Berdasarkan Tabel 3. Diperoleh nilai Signifikansi } \\
\text { sebesar 0.951 maka nilai dari 0.951> 0.05 . Maka } \\
\text { dapat disimpulkan bahwa data berdistribusi Normal. }\end{array}$
\end{tabular}

\section{B. Uji Heteroskedasitas}

Uji Heteroskedastisitas digunakan untuk menguji apakah dalam sebuah regresi terjadi ketidaksamaan varian dari residual dari suatu pengamatan ke pengamatan lain (Ghozali, 2011:139).Prasyarat yang harus terpenuhi dalam model regresi adalah tidak adanya gejala heteroskedastisitas.

Untuk mendeteksi adanya Heteroskedastisitas dilakukan uji glejser. Uji glejser dilakukan dengan cara meregresikan variabel independen dengan nilai absolut residualnya (ABS_RES). Jika nilai signifikansi antara variabel independen dengan absolut residual lebih dari 0.05 maka tidak terjadi masalah heteroskedastisitas.

Tabel 4. Hasil Uji Heteroskedasitas

\begin{tabular}{lcc}
\hline Variabel & $\begin{array}{c}\text { Signifikans } \\
\text { i }\end{array}$ & Keterangan \\
\hline $\begin{array}{l}\text { Kepuasan } \\
\text { Masyarakat }\end{array}$ & 0.679 & $\begin{array}{c}\text { Tidak terjadinya } \\
\text { Heteroskedastisita } \\
\text { s }\end{array}$ \\
\hline
\end{tabular}

Sumber : Hasil Uji SPSS 20.0 terhadap Uji

Heteroskedasitas Tahun 2021

Berdasarkan Tabel 4. Dapat disimpulkan bahwa model yang digunakan tidak adanya terjadi Heteroskedastisitas.

\section{Konsep Dasar Perhitungan \\ 1. Persamaan Regresi Sederhana}

Menurut Sujarweni, 2015) menyatakan bahwa regresi bertujuan untuk menguji pengaruh antara satu variabel dengan variabel lain. Variabel yang dipengaruhi disebut variabel tergantung atau dependen. Sedangkan variabel bebas Inependen. Model persamaan regresi linier sederhana dapat dirumuskan sebagai berikut :

Model Regresi pada penelitian ini adalah :

$Y=a+b X$

Adapun: $\mathrm{Y}$ : Variabel dependen

$\mathrm{X}$ : Variabel Independen

a : Konstanta

b : Nilai Koefisien Regresi

Tabel 5. Hasil Uji Analisis Regresi Sederhana

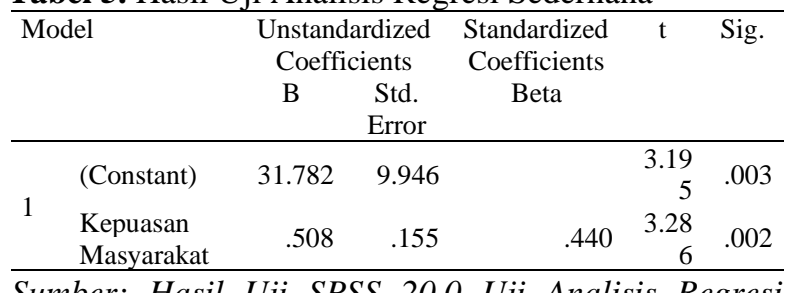

Sumber: Hasil Uji SPSS 20.0 Uji Analisis Regresi Sederhana 
Berdasarkan tabel 5, diperoleh persamaan sebagai berikut :

$$
\mathrm{Y}=31.782+0.508 \mathrm{X}
$$

Dilihat dari persamaan diatas maka dapat dijelaskan sebagai berikut :

1. Berdasarkan Uji Analisis Regresi Sederhana diatas diketahui bahwa nilai konstan sebesar 31.782. Artinya Jika Variabel Bebas (Kepuasan Masyarakat) dianggap konstan maka dapat diprediksi nilai variabel Informasi sebesar 31.782. Sehingga dapat dikatakan jika semakin tinggi nilai Variabel Bebas, maka akan semakin tinggi pula Kepuasaan Masyarakat.

2. Variabel Kepuasan Masyarakat (X) pada Uji Analisis Regresi Sederhana diatas diketahui bahwa nilai Koefisien sebesar 0.508. Artinya nilai variabel Kepuasan Masyarakat meningkat dan yang lain konstan. Maka dapat diprediksi nilai Variabel Kepuasan Masyarakat naik sebesar 0.508 .

\section{Uji T}

Uji statistik $t$ menunjukkan seberapa jauh pengaruh variabel independen secara individual menerangkan variansi variabel dependen (Ghozali,2009). Apabila nilai signifikan $<0.05$ maka variabel independen berpengaruh terhadap variabel dependen.Apabila nilai signifikan $>0.05$ maka variabel independen tidak berpengaruh terhadap variabel dependen.

\section{Pengujian Hipotesis Pertama}

Rumusan hipotesisnya sebagai berikut :

$H_{0}$ : Tidak ada terjadinya Pengaruh Pendaftaran Tanah Sistematis Lengkap (PTSL)

Terhadap Kepuasan Masyarakat

$H_{1}$ : Adanya Pengaruh Pendaftaran Tanah Sistematis Lengkap (PTSL) Terhadap Kepuasan Masyarakat

Berdasarkan tabel.5 hasil uji analisis regresi sederhana, diperoleh hasil untuk uji $\mathrm{T}$ adalah variabel Kepuasan Masyarakat yang mempunyai nilai signifikan sebesar $0.002<0.05$.Maka $H_{0}$ ditolak dan $H_{1}$ diterima dan dapat disimpulkan bahwa Kepuasan Masyarakat berpengaruh terhadap Pendaftaran Tanah Sistematis Lengkap (PTSL).

\section{Uji Koefisien Korelasi}

Triyono (2016) menyatakan bahwa korelasi adalah "derajat hubungan linier antara dua variabel atau lebih dari data hasil pengamatan". Sedangkan menurut (Sulistyastuti, 2017) mendefinisikan bahwa "koefisien korelasi adalah analisa yang dilakukan untuk mengukur derajat hubungan atau kekuatan asosiasi linier antara dua varaibel".Analisa korelasi juga menunjukkan arah hubungan (positif atau negatif) antara variabel dependen dengan variabel-variabel independen.Koefisien korelasi disimbolkan dengan " $r$ ". Oleh karena itu untuk memudahkan interprestasi seberapa kuat hubungan korelasinya maka dapat digunakan pedoman sebagai berikut :

Tabel 6. Interprestasi Koefisien Korelasi

Interval Koefisien Tingkat Hubungan

\begin{tabular}{cc}
\hline $0,00-0,020$ & Sangat Lemah \\
$0,21-0,40$ & Lemah \\
$0,41-0,070$ & Kuat \\
$0,71-0,90$ & Sangat Kuat \\
$0,91-0,99$ & Kuat Sekali \\
1 & Sempurna \\
\hline
\end{tabular}

Sumber: Sujarweni (2015:93)

Nilai koefisien korelasi dapat dihitung dengan bantuan Sofware SPSS versi 20.0 dengan korelasi Bivariat-pearson Correlattion dan outputnya sebagai berikut :

Tabel 7. Koefisien Korelasi

\begin{tabular}{|c|c|c|c|}
\hline & & $\begin{array}{c}\text { Kepuasan } \\
\text { Masyarakat }\end{array}$ & $\begin{array}{c}\text { Informasi } \\
\text { PTSL }\end{array}$ \\
\hline \multirow{3}{*}{$\begin{array}{l}\text { Kepuasan } \\
\text { Masyarakat }\end{array}$} & $\begin{array}{l}\text { Pearson } \\
\text { Correlation }\end{array}$ & 1 & $.440^{* * *}$ \\
\hline & Sig. (2-tailed) & & .002 \\
\hline & $\mathrm{N}$ & 47 & 47 \\
\hline \multirow{3}{*}{$\begin{array}{l}\text { Informasi } \\
\text { PTSL }\end{array}$} & $\begin{array}{l}\text { Pearson } \\
\text { Correlation }\end{array}$ & $.440^{* *}$ & 1 \\
\hline & Sig. (2-tailed) & .002 & \\
\hline & $\mathrm{N}$ & 47 & 47 \\
\hline
\end{tabular}

Sumber: Hasil Uji Koefisien Korelasi Menggunakan SPSS 20.0 Tahun 2021

Berdasarkan hasil perhitungan data menggunakan SPSS 20.0 sesuai table 7. diatas dapat kita simpulkan bahwa adanya hasil uji Pearson Correlattion semua faktor-faktor kepuasan masyarakat dengan Informasi Pendaftaran Tanah Sistematis Lengkap menunjukkan bahwa terlihat hubungan yang kuat dan searah antar variabel Independen (Kepuasan Masyarakat) dengan variabel Dependen (Informasi PTSL) yaitu sebesar 0.440 yang termasuk kategori 0.41-0.70 .

\section{Uji Koefisien Determinasi}

Menurut (Hasan, 2016) koefisien determinasi menyatakan bahwa "penyebab perubahan variabel $\mathrm{Y}$ yang datang dari variabel $\mathrm{X}$ 
sebesar kuadrat koefisien korelasinya".Koefisien determinasi ini menjelaskan besarnya pengaruh nilai suatu variabel (Variabel $\mathrm{X}$ ) terhadap naik/turunya (variabel Y). Rumusnya sebagai berikut :

$K D=r^{2} \times 100 \%$

Keterangan :

KD : Koefisien Dterminasi

R : Nilai Koefisien Korelasi nilai koefisien penentu ini terletak antara 0 dan +

$$
1(0 \leq K P \leq+1)
$$

$100 \%$ : Pengali yang menyatakan dalam presentase

Tabel 8. Hasil Uji Koefisien Determinasi

\begin{tabular}{|c|c|c|c|c|}
\hline Model & $\mathrm{R}$ & $\begin{array}{l}\mathrm{R} \\
\text { Square }\end{array}$ & $\begin{array}{l}\text { Adjusted } \mathrm{R} \\
\text { Square }\end{array}$ & $\begin{array}{l}\text { Std. Error of the } \\
\text { Estimate }\end{array}$ \\
\hline 1 & $.440^{\mathrm{a}}$ & .193 & .176 & 3.19480 \\
\hline
\end{tabular}

a. Predictors: (Constant), Kepuasan Masyarakat

Sumber: Hasil Uji SPSS 20.0 Koefisien Determinasi Tahun 2021

Berdasarkan tabel 3.8 dapat diketahui bahwa besarnya pengaruh variabel Kepuasan Masyarakat terhadap variabel Informasi Pendaftaran Tanah Sistematis Lengkap (PTSL) di Desa Seunebok Punti adalah Sebesar 0.193 atau $19.3 \%$ dan sisanya $80.7 \%$ dipengaruhi oleh variabel-variabel lain yang tidak dimasukkan kedalam penelitian ini.

\section{KESIMPULAN DAN SARAN}

\subsection{Kesimpulan} berikut:

Kesimpulan yang diperoleh adalah sebagai

1. Berdasarkan analisis laporan, kepuasan masyarakat dinilai sudah baik dalan penyampaian Informasi Pendaftaran Tanah Sistematis Lengkap (PTSL) pada Desa Seuneubok Punti Kabupaten Aceh Tamiang.

2. Pada pengujian persamaan regresi yaitu $\mathrm{Y}=$ $31.782+0.508 \mathrm{X}$ menunjukkan bahwa, jika Kepuasan Masyrakat $=0$ maka Informasi PTSL adalah 31.782 dan setiap penambahan (karena Positif) Kepuasan Masyarakat sebesar $1 \%$ maka akan meningkatkan Informasi PTSL sebesar 0.508.

3. Pada pengambilan hipotesis ternyata dapat dilihat $\mathrm{t}$ hitung $<\mathrm{t}$ tabel adalah $0.002<0.05$ yang dapat diartikan sebagai $H_{0}$ ditolak dan $H_{1}$ diterima maka Kepuasan Masyarakat Berpengaruh terhadap Pendaftaran Tanah Sistematis Lengkap (PTSL).
4. Pada pengujian Koefisien korelasi Pearson Product Moment diperoleh hasil sebesar 0.440 berada pada interval 0.41-0.70 yang menunjukkan bahwa terdapat hubungan yang kuat antara Kepuasan Masyarakat (X) dengan Informasi Pendafatran Taah Sistematis Lengkap (PTSL) (Y).

5. Pada Pengujian analisis koefisien determinasi diperoleh persentase besarnya pengaruh kepuasan masyarakat terhadap informasi PTSL. Melalui perhitungan tersebut diperoleh besar persentasenya adalah $19.3 \%$ dan sisanya 80.7\% dipengaruhi oleh variabel-variabel yang tidak dimasukkan kedalam penelitian ini.

\subsection{Saran}

Dari hasil laporan ini, saran yang dapat disampaikan oleh penulis untuk Kantor Pertanahan Kabupaten Aceh Tamiang untuk terus dapat meningkatkan Kualitas Pelayanan maupun penyampaian Informasi untuk masyarakat Kabupaten Aceh Tamiang.

\section{REFERENSI}

Hasan, M.I. (2016).Pokok-Pokok Materi Statistik (Statistik Inferensif). Jakarta: PT. Bumi Aksara

Riyanto, A. (2018). Implikasi Kualitas Pelayanan Dalam Meningkatkan Kepuasan Pelanggan Pada PDAM Cibadak Sukabumi.Jurnal Ecodemica, 2(1), 117124.

Semil, N. (2018).Pelayanan Prima Instansi Pemerintah. Depok: Prenada Media Group.

Sujarweni, W. (2015).SPSS untuk Penelitian.

Sulistyastuti, D. R. dan E. A. P. (2017). Metode Penelitian Kuantitatif Untuk Administrasi Publik dan Masalah Masalah Sosial. Yogyakarta: Gaya Media.

Triyono, R. (2016). Metodologi Penelitian Kuantitatif. Depok: Papas Sinar Pinanti. 